\title{
Seroprevalence of SARS-CoV-2 Antibodies and Factors Associated with Seropositivity at the University of Salamanca: The DIANCUSAL Study
}

\section{Vicente Santiago Belen}

University of Salamanca

Pendones Josue

University of Salamanca

Adserias Francisco

University of Salamanca

Gonzalez Hernandez

University of Salamanca

Miguel Rodriguez

University of Salamanca

Jose Luis Vicente Villardon

University of Salamanca

Javier Burgillo

University of Salamanca

Javier Lopez Andaluz

University of Salamanca Jose Angel Martin Oterino University of Salamanca

Francisco Garcia Criado

University of Salamanca

Fausto Barbero

University of Salamanca

Ana Morales

University of Salamanca

Purificación Galindo

University of Salamanca

Rogelio Gonzalez

University of Salamanca

Moncef Belhassen ( $\boldsymbol{\sigma}$ belhassen@usal.es)

University of Salamanca

Antonio Muro 
University of Salamanca

Juan Luis Muñoz

University of Salamanca

\section{Research Article}

Keywords: SARS-CoV-2, COVID-19, antibodies, seroprevalence, screening, university, Salamanca, Spain

Posted Date: May 7th, 2021

DOl: https://doi.org/10.21203/rs.3.rs-489321/v1

License: (a) (1) This work is licensed under a Creative Commons Attribution 4.0 International License. Read Full License 


\section{TITLE}

Seroprevalence of SARS-CoV-2 antibodies and factors associated with seropositivity at the University of Salamanca: The DIANCUSAL study

\section{SHORT TITLE}

SARS-CoV-2 seroprevalence at Salamanca University, Spain.

\section{ABSTRACT}

Background: Systematic screening for antibodies against SARS-CoV-2 is a crucial tool for surveillance of the COVID-19 pandemic. The University of Salamanca (USAL) in Spain designed a project called "DIANCUSAL" (Diagnosis of New Coronavirus, COVID-19, in University of Salamanca) to measure antibodies against SARS-CoV-2 among its $~ 34,000$ students and academic staff, as the influence of the university community in the spread of the SARS-CoV-2 pandemic in the city of Salamanca and neighbouring towns hosting USAL campuses could be substantial.

Objective: The aim of this study was to estimate the prevalence of SARS-CoV-2 antibodies among USAL students, professors and staff and to evaluate the demographic, academic, clinical and lifestyle and behavioural factors related to seropositivity.

Methodology: The DIANCUSAL study is an ongoing university population-based cross-sectional study, with the work described herein conducted from July-October 2020. All USAL students, professors, and staff were invited to complete an anonymized questionnaire. Seroprevalence of anti-SARS-CoV2 antibodies was detected and quantified by using chemiluminescent assays for IgG and IgM.

Principal findings: A total of 8197 (24.71\%) participants were included. The mean age was 31.4 (14.5 SD) years, and $66.0 \%$ of the participants were female. The seroprevalence was $8.25 \%$ overall, and was highest for students from the education campus (12.5\%) and professors from the biomedical campus $(12.6 \%)$, with significant differences among faculties $(p=0.006)$. Based on the questionnaire, loss of smell and fever were the symptoms most strongly associated with seropositivity, and $22.6 \%$ of seropositive participants were asymptomatic. Social distancing was the most effective hygiene measure $(p=0.0007)$. There were significant differences in seroprevalence between participants with 
and without household exposure to SARS-CoV-2 ( $p=0.0000)$, but not between students who lived in private homes and those who lived in dormitories. IgG antibodies decreased over time in the participants with confirmed self-reported COVID-19 diagnoses.

Conclusions: The analysis revealed an overall 8.25\% seroprevalence at the end of October 2020, with a higher seroprevalence in students than in staff. Thus, there is no need for tailored measures for the USAL community as the official average seroprevalence in the area was similar $\left(7.8 \%\right.$ at $22^{\text {nd }}$ June and 12.4 at $15^{\text {th }}$ November of 2020. Instead, USAL members should comply with public health measures.

\section{KEYWORDS}

SARS-CoV-2; COVID-19; antibodies; seroprevalence; screening; university; Salamanca; Spain.

\section{FUNDING}

The DIANCUSAL (Diagnosis of New Coronavirus, COVID-19, in University of Salamanca) study was funded by a grant from the University of Salamanca (USAL).

\section{CONFLICT OF INTEREST}

The authors declare they have no conflicts of interest. 


\section{INTRODUCTION}

In December 2019, a novel coronavirus, severe acute respiratory syndrome coronavirus 2 (SARS-CoV2), emerged that causes the illness designated COVID-19 and that has had devastating socioeconomic and public health consequences (1). A pandemic was declared by the WHO in March 2020 after rapid human-to-human transmission and the intercontinental spread of the virus. More than 121 million people have been infected worldwide, with more than 3.0 million deaths (2). In Spain, the first SARSCoV-2 case was identified on January $31^{\text {st }}$ and was determined to have been imported from Germany. Since then, the number of cases has increased rapidly in the country, and Spain is now one of the European countries most affected by the COVID-19 pandemic (3).

Control measures such as the use of masks, physical distancing, contact tracing, and isolation in terms of people who have tested positive instead. However, these actions have been variably implemented and have proven insufficient in impeding the spread of COVID-19. Systematic screening for antibodies against SARS-CoV-2 is a crucial tool for surveillance of the pandemic and to predict when herd immunity might be reached (4). A sero-epidemiological study provides information on the proportion of the population exposed and, if the antibodies are a marker of total or partial immunity, the amount of the population that remains susceptible to the virus. Since there is limited access to diagnostic tests, serological surveys are a valuable tool to assess the extent of the epidemic (5), and they have an advantage over epidemiological surveillance of confirmed COVID-19 cases that captures only a proportion of all infections. Seroprevalence studies have been conducted since the onset of the pandemic, mostly with health workers and the general population (6,7). A nationwide, population-based sero-epidemiology study called "ENE-COVID" was carried out to analyse the prevalence of SARS-CoV-2 in Spain, showing remarkable differences between higher- and lowerprevalence areas (3).

Few seroprevalence studies have been carried out in academic institutions such as universities, and those that have been carried have been conducted with small cohorts (8-12). Such studies are needed because university communities (faculty, staff and students) could be expected to be among the groups most exposed to SARS-CoV-2. In April 2020, the World Bank estimated that universities and other tertiary educational institutions were closed in 175 countries and communities and that studies were ended or significantly disrupted due to COVID-19 for more than 220 million postsecondary education students (13). Spain was one of the countries with the strictest conditions 
during the first wave (March-April 2020), and leaving home was allowed only for essential needs. All universities were closed, and classes continued online with support from academic services.

The University of Salamanca (USAL) is located in western Spain and has 30,000 students and over 3000 academic staff. USAL comprises a main campus in the city of Salamanca $\left(40^{\circ} 50^{\prime} 0^{\prime \prime} \mathrm{N}, 6^{\circ} 0^{\prime} 0^{\prime \prime} \mathrm{W}\right)$ and three smaller campuses in Avila $\left(40^{\circ} 39^{\prime} 15.65^{\prime \prime} \mathrm{N}, 4^{\circ} 41^{\prime} 46.4^{\prime \prime} \mathrm{W}\right)$, Zamora $\left(41^{\circ} 45^{\prime} 0^{\prime \prime} \mathrm{N}, 6^{\circ} 0^{\prime} 0^{\prime \prime} \mathrm{W}\right)$ and Bejar $\left(40^{\circ} 23^{\prime} 5^{\prime \prime} N, 5^{\circ} 45^{\prime} 43^{\prime \prime} \mathrm{W}\right)$, all of which were assessed in this study. The ratio of students to Salamanca city inhabitants is 1:5, which is higher than that of other cities in Spain. Therefore, the influence of the university community in the spread of the SARS-CoV-2 pandemic in Salamanca could be substantial.

To measure antibodies in the university community, teams of professor and student volunteers from the health sciences faculties of USAL conducted the DIANCUSAL project. The aim was to characterize the university community to provide a basis for the eventual implementation of strategies to mitigate cases of COVID-19 at USAL. Thus, the primary objective was to estimate the prevalence of SARS-CoV2 antibodies among members of USAL and compare it with that of the general population. The secondary objective was to evaluate the demographic, academic, clinical and lifestyle and behavioural factors related to seropositivity detection among members of the USAL community.

\section{MATERIAL AND METHODS}

\section{Study design and population}

The DIANCUSAL (Diagnosis of New Coronavirus, COVID-19, in University of Salamanca) project is an ongoing university population-based cross-sectional study. A total of 33,178 students, professors, and staff at USAL were invited by e-mail to enrol in the study. The participants were volunteers and registered online. The flow chart in figure 1 indicates the inclusion and exclusion criteria. The participants were enrolled in the current study on July $14^{\text {th }}$ and participated until October $30^{\text {th }}, 2020$.

\section{Data collection}

The anonymized questionnaire focused on COVID-19 was available online on a website designed specifically for DIANCUSAL, https://diancusal.usal.es. The completion of the questionnaire was required for participation in the study, and those who did not complete the questionnaire were 
excluded. The participants were asked questions about their clinical and sociodemographic characteristics, symptoms related to SARS-CoV-2 infection, comorbidities, medication use, behavioural factors, etc. All questions are shown in supplementary figure 1.

\section{Serological testing}

Anti-SARS-CoV-2 antibodies were detected and quantified by using chemiluminescent assays for IgG (LIAISON ${ }^{\circledR}$ SARS-CoV-2 S1/S2 IgG) and IgM (LIAISON ${ }^{\circledR}$ SARS-CoV-2 IgM). LIAISON ${ }^{\circledR}$ SARS-CoV-2 S1/S2 IgG is a quantitative test that specifically identifies antibodies against the S1 and S2 proteins of the SARS-CoV-2 spike, which are responsible for the binding and fusion of the virus to the host cell. The spike protein and its subunits are considered the main antigen targets for neutralizing antibodies. LIAISON ${ }^{\circledR}$ SARS-CoV-2 IgM is a qualitative method that detects IgM antibodies against spike proteins. Both methods were performed using a LIAISON XL analyser (Diasorin, Italy).

\section{Statistical analysis}

The results were expressed as the absolute value (n) and percentage (\%) with $95 \% \mathrm{Cl}$ for categorical variables and as the mean, standard deviation (SD), median, interquartile range (IQR) (Q3-Q1), and range (minimum value, maximum value) for continuous variables. A chi-square $\left(\chi^{2}\right)$ test was used to compare the associations between categorical variables, such as clinical and demographic variables, and the measured outcome was expressed as the odds ratio (OR) and its $95 \% \mathrm{Cl}$. Continuous variables were compared with Student's t-test or the Mann-Whitney test for two groups, depending on whether they had a normal or non-normal distribution. Additionally, we applied the corresponding logistic regression model for multivariate analysis of categorical variables. We considered a statistically significant difference to occur at a $p$-value $<0.05$. Data analysis was performed using SPSS 27 (Statistical Package for the Social Sciences).

\section{Ethics statement}

All participants enrolled in the study voluntarily, and written informed consent was required for the data to be used for analysis. Neither participation in the study nor results were reported to the participants' employer. The study protocol was approved by the Ethical Review Board of Complejo Asistencial Universitario de Salamanca (CAUSA, Salamanca Spain CEIMc; code 202007 539). The procedures were carried out in accordance with the ethical standards described in the Revised Declaration of Helsinki in 2013. All clinical and epidemiological data were anonymized. 


\section{Role of the funding source}

The funders facilitated data acquisition but had no role in the study design, data analysis or interpretation, or writing of the manuscript.

\section{RESULTS}

\section{Demographic data}

From the 33,178 students, professors, and staff of USAL who were invited to take part in the study between $15^{\text {th }}$ of July 2020 and $30^{\text {th }}$ of October 2020 , a total of 8197 (24.71\%) participants were finally included (table 1). Most of the participants were undergraduate students (5093, 62.1\%), and most participants were aged 17 to 28 years (68.1\%). The most represented group was technicians and administrative officers (1017 of 1210, 84.05\%), followed by professors and researchers (1553 of $2300,67.52 \%$ ), undergraduate students (5093 of 20849, 24.43\%) and postgraduate students (392 of 4692, 8.35\%). The mean age was 31.4 (14.5 SD) years; $66.0 \%$ of the participants were female.

\section{Seroprevalence}

Seropositivity for IgM and/or IgG antibodies was found in 676/8197 of the participants, corresponding to $8.25 \%$ of the sample (95\% Cl: $7.65-8.84)$, with IgM detected in $1.04 \%$ (95\% Cl: $0.82-$ 1.26), IgG detected in $7.98 \%(95 \% \mathrm{Cl}$ : $7.39-8.57)$ of participants, and both in only $0.77 \%(95 \% \mathrm{Cl}$ : 0.58-0.96; 63/8197 participants). The highest seropositivity was found in males aged 17 to 28 years. The highest seropositivity was found in males aged 17 to 28 years ( $n=149,9.3 \%$, (95\% Cl: 7.92-10.78)] but no significant differences were found by age or sex. Seroprevalence by sex and age for each of the measured antibodies is presented in supplementary figure 2.

Additionally, the percentages of participants who tested positive for IgG, those who tested positive for IgM, and those who tested positive for IgG and/or IgM over time (July-October 2020) are presented in supplementary figure 3. Of the participants with previous confirmed SARS-CoV-2 infection, IgG seroprevalence was $83.3 \%$ (95\% Cl: 66.1-100) in July, suggesting that $16.7 \%$ (95\% Cl: 033.9) of these individuals had lost the antibodies since initial infection. Additionally, $69.6 \%$ (95\% Cl: 62.5-76.6) of the participants with previous confirmed infection showed IgG seropositivity in October, meaning $30.4 \%$ (95\% Cl: 23.3-37.5) of these participants had lost the antibodies since initial infection.

\section{Associations of academic factors with seropositivity}


We found statistically significant differences in seropositivity among academic positions $(p=0.020)$. The highest seropositivity rate occurred in the postgraduate students [9.9\% (95\% Cl: 7.0-12.9)], followed by the undergraduate students [8.9\% (95\% Cl: 8.1-9.7)]. The lowest rate was observed in the technicians and administrative officers $[6.5 \%(95 \% \mathrm{Cl}: 5.0-8.0)]$. The seroprevalence in the professors/researchers was $7.3 \%$ (95\% Cl: 6.0-8.6).

Of the cities in which the USAL campuses are located, Salamanca was home to the highest proportion of participants in the study (90.2\%). The highest positivity rate was in Avila [10.8\% (95\% Cl: 7.5-14.1)], and the lowest was in Bejar [4.2\% (95\% Cl: 0.6-7.9)]. Zamora had a positivity rate of $9.9 \%(95 \% \mathrm{Cl}$ : 6.8-13.0), and Salamanca had a positivity rate of $8.1 \%$ (95\% Cl: 7.5-8.7) (figure 2); however, this difference among the cities was not statistically significant $(p=0.082)$. The seroprevalences of professors and students were compared in each city. Higher seropositivity rates were observed in Salamanca and Zamora, and lower rates were observed in Avila and Bejar.

Seroprevalence was analysed for each campus in Salamanca city (figure 2). The largest proportion of participants came from the biomedical campus (24.2\%), followed by the social sciences campus (19.1\%). The education, social sciences, science and biomedical campuses had seroprevalences over $8 \%$. The highest seroprevalence was found for male students from the education campus [12.5\% (95\% Cl: 3.8-21.2)] and male professors from the biomedical campus [12.6\% (.95\% Cl: 7.0-18.2)]. Additionally, male professors from the psychology and arts campus and female professors from the geography and history campus had the lowest seroprevalence (0.0\%) (figure $3 \mathrm{~A})$.

There were highly significant differences in the positivity rates across the various faculties $(p=0.006)$ (figure 3B). We observed the highest seropositivity rate in the nursing and physiotherapy faculty [13.3\% (95\% Cl: 10.1-16.5)], followed by the education faculty [10.6\% (95\% Cl: 8.4-12.8)]. The lowest prevalence was observed in the psychology, geography and history, and languages faculties [5.7\% (95\% Cl: 3.6-7.7), 6.1\% (95\% Cl: 2.9-9.2) and 6.5\% (95\% Cl: 4.5-8.5), respectively]. Moreover, the highest seropositivity rate was found for male professors from the nursing and physiotherapy faculty [26.7\% (95\% Cl: 4.3-49.1)], while the lowest percentage was found for male professors from the psychology faculty $(0.0 \%)$.

\section{Associations of clinical factors with seropositivity}


Data comparing seroprevalence by self-reported blood type and BMI are shown in supplementary table 1. Most of the participants had A [47.3\% (95\% Cl: 45.9-48.6)] or O [40.3\% (95\% Cl: 39.0-41.7)] blood type, and no significant differences in seropositivity were found among blood types. BMI ranged from 18.5 to 24.9 [67.0\% (95\% Cl: 66.0-68.1)]; logistic regression analysis revealed no significant relationship between BMI and seropositivity.

Seroprevalence was also studied according to the self-reported presence of symptoms, diseases, and drug prescriptions. Among the 676 seropositive participants, 153 (22.6\%) were asymptomatic, and 523 (77.4\%) were symptomatic. Figure 4A shows ORs for the associations of seropositivity with the main symptoms. Loss of smell (5.3\% vs 54\%; OR 20.69 [15.95-26.89] and fever (5.9\% vs 16\%; OR 3.02 [2.45-3.72]) were the symptoms most strongly associated with seropositivity. No significant associations were found between seropositivity rates and the overall frequencies, comorbidities, or prescriptions of corticosteroids, inhalers or antihistamines.

\section{Associations of lifestyle and behavioural factors with seropositivity}

The participants' smoking status and alcohol consumption were also studied. No significant difference in seropositivity was found between alcohol consumers and non-consumers $[8.1 \%$ for alcohol consumers vs 8.3\% for non-consumers; OR 0.93 (95\% Cl: 0.67-1.29)]. However, a difference was found between smokers and non-smokers, and interestingly, seropositivity more strongly associated with non-smoking [5.2\% for current smoker's vs $8.6 \%$ for non-smokers; OR 0.57 (95\% Cl: $0.42-0.79)]$.

Seroprevalence according to hygiene measures is presented in figure 4B. We identified a significantly decreased seroprevalence in people who adopted social distancing $(p=0.0007)$, but no other major differences. Table 2 shows the association of the type of residence and the numbers of cohabitants and pets with seroprevalence. There were significant differences in seroprevalence between participants with and without household exposure to SARS-CoV-2 $(p=0.0000)$. In the student group, there were no differences in seroprevalence between those who lived in private homes and those who lived in dormitories.

\section{DISCUSSION}

Our cross-sectional study was carried out between June and October 2020 using chemiluminescent assays for antibody detection and a questionnaire. The overall objective of our study was to carry out 
a comprehensive study of the university community to guide strategies to mitigate possible cases of COVID-19 at USAL for safe reopening in the 2020/2021 academic year. We analysed the demographic, academic, clinical and lifestyle and behavioural factors associated with COVID-19 in a university sample, with a high participation rate. It was found that i) the overall seroprevalence of anti-SARSCoV-2 antibodies (IgG and/or IgM) was $8.25 \%$ - this rate is similar to that in studies of larger communities (14); ii) antibody seropositivity decreased over time; iii) there was a higher seroprevalence in students and professors in health-related campuses and faculties than in other campuses and faculties; iv) the seroprevalence was similar across campuses, but there were highly significant differences among faculties; v) asymptomatic status was observed in $22.6 \%$ of the seropositive participants, and loss of smell was the main symptom associated with antibody detection; and vi) the only hygiene measure associated with lower seroprevalence was social distancing.

Seroprevalence studies are currently being implemented worldwide, as they are considered a valuable tool to reveal the extent of SARS-CoV-2 infection via the estimation of the proportion of the population exposed to the virus. To the best of our knowledge, this is the largest study describing the prevalence of SARS-CoV-2 in an academic population in Europe. The seroprevalence of the university community observed in our study and that previously found for the general population were very similar (14). However, the USAL seroprevalence rate was higher than the seroprevalence rates of other academic communities, such as the University of Southern California (10) and the University of Pennsylvania (11) in the USA, the University of Athens in Greece (12) and the University of Alicante in Spain (8) (2.6-5.5\%) but lower than that of the University of Sergipe in Brazil (22.5\%) (9). These differences could be due to the following: i) some studies included a smaller number of participants; ii) the previous studies were carried out exclusively with students; iii) the serological tests used varied across studies with different levels of sensitivity; and iv) studies were performed over different periods of time.

One main finding of this study was a difference in seropositivity between students and university staff. The highest rate was found in postgraduate students, followed by undergraduate students, and the lowest rate was observed in technicians and administrative officers. Students' large social networks could be a primary cause of these results. We initially expected that students could be responsible for the spread of infection in our region. However, our results indicate that student 
communities had exhibited more protective behaviour against the spread of the pandemic than other groups.

In addition, while we found that seropositivity did not significantly differ across cities, the highest seroprevalence was found in the participants from Avila, probably due to the proximity of this town to the capital of Spain, Madrid. It is well known that Madrid had a higher seroprevalence in the first wave of the pandemic than other Spanish cities due to the centrifugal spread of the virus (3). Social factors, such as the population structure and poverty, which were not considered in our study, might also explain the higher prevalence in Avila.

In terms of subject area, our comparison of the seroprevalence across Salamanca campuses showed the highest seropositivity rates for students from the education campus and male professors from the biomedical campus. The first clinical cases detected at USAL were in the education faculty, and the PCR technique was not systematically used to identify students with contact with the index patient, which allowed the infection to spread. In addition, higher seroprevalence was found in professors from biomedical campuses, particularly in the nursing and physiotherapy faculty, due to their interactions with hospital environments.

We also investigated the association of clinical and lifestyle factors, such as comorbidities, BMI, blood type, smoking, and alcohol consumption, with seropositivity. Previous research has shown that comorbidities occur with SARS-CoV-2 infection in approximately half of inpatients. Hypertension was found to be the most common comorbidity, followed by obesity, diabetes and coronary heart disease (15). Moreover, in a different study, obesity and adiposity-related diseases were shown to be clearly related to worse disease evolution (16). In our study, no differences in seroprevalence according to weight (represented as BMI) and groups of diseases consistently linked to the prescription of certain medications were observed. Patients with a smoking history had a higher likelihood of developing more severe symptoms of COVID-19 disease than non-smokers. However, data on whether COVID19 has a greater incidence in smokers than non-smokers have thus far been contradictory and inconclusive (17). Surprisingly, our data showed tobacco use to be a protective factor, demonstrating the need for more studies to clarify the role of smoking in the incidence of COVID-19. Interestingly, previous research showed that the ABO blood group was associated with SARS-CoV-2 infection and survival (18). Group A has been found to be more common, while group $\mathrm{O}$ has been found to be less common among infected individuals. Moreover, blood group O has shown lower mortality than the 
other $A B O$ blood groups. In our study, the $A B O$ blood group did not show any relationship to seroprevalence.

Furthermore, we examined the association of various symptoms with seropositivity. The most common symptoms among young SARS-CoV-2 patients were previously found to involve the ear and nose (19)In our cohort, which was composed primarily of students, the main clinical manifestation linked with higher seroprevalence was loss of smell. Interestingly, $22.6 \%$ of the participants who presented antibody positivity did not report any symptoms. This finding suggests that asymptomatic infection is relatively common in a healthy population. Thus, among asymptomatic individuals, infections could resolve spontaneously without complications, as occurs in other coronavirus infections. Therefore, the rapid identification of asymptomatic individuals is essential to control the spread of infection. Moreover, clinical characteristics could influence the real prevalence of this disease. Additionally, aspects of infection, such as immunity, reinfection and cross-reactivity with human endemic coronavirus, are not yet known (20).

Governments across the world have implemented a wide range of measures to mitigate the spread of SARS-CoV-2 infection, but the optimal non-pharmaceutical strategies are not entirely clear (21). Our findings highlight differences between adults in the academic community who received positive SARS-CoV-2 test results and those who received negative SARS-CoV-2 test results. Our data showed that among various hygiene measures, such as the use of hydroalcoholic gel, masks and gloves, only social distancing was associated with a significantly decreased seroprevalence. Continued assessment of the activities and exposure of communities, schools, and workplaces during reopening is important. Exposure and activities where mask use and social distancing are difficult to maintain, including going to locations that offer on-site eating and drinking, might be important risk factors for SARS-CoV-2 infection. Hence, implementing safe practices to reduce exposure to SARS-CoV-2 during on-site eating and drinking should be considered to protect customers, employees, and communities and to slow the spread of COVID-19 (22).

Regarding the place of transmission, our data showed significant differences between participants with and without household exposure to SARS-CoV-2. These results are consistent with other reports suggesting that households are the principal place of transmission (23). Interestingly, we also noted that in the student group, there were no differences between those who lived in private homes and those who lived in dormitories, which is in contrast to the assumption that colleges would be 
environments with a higher risk of infection since they are spaces characterized by a greater amount of social interaction.

Seroprevalence over time is the main indicator of the maintenance of specific antibodies against SARS-CoV-2. Our results were similar to those of other studies that showed a decrease in IgG antibodies over time (24). The epidemiological impact of the decrease in seroprevalence over time in academic communities must be elucidated.

Several limitations of this study must be considered. By design, this study was carried out in a specific population. Thus, the results cannot be extrapolated directly to the general population. The serological tests we used in this study could also be a limitation. However, chemiluminescent assays were shown to have higher sensitivity and specificity rates than other methods (25). Additionally, data were obtained through a self-report questionnaire completed by the participants. Neither ethnicity nor income data were collected, preventing the analysis of previously demonstrated associations with COVID-19 positivity (26).

In summary, our analysis of more than 8100 USAL community members estimated the exposure of members of this community to SARS-CoV-2, revealing approximately $8 \%$ seroprevalence from JulyOctober 2020 and a higher prevalence in students than in university staff. Our findings suggest that there is no need for tailored measures for USAL members who should comply with public health measures, especially the maintenance of social distancing, as well as implement new measures, such as vaccination. Importantly, as the higher education population is not among the most vulnerable groups or among those who will have priority access to vaccination, it will be necessary to continue to maintain active epidemiological surveillance and follow-up of cases and contacts in this population.

\section{REFERENCES}

1. Zhu N, Zhang D, Wang W, Li X, Yang B, Song J, Zhao X, Huang B, Shi W, Lu R, et al. A Novel Coronavirus from Patients with Pneumonia in China, 2019. New Engl J Med (2020) 382:727-733. doi:10.1056/nejmoa2001017

2. Organization WH. https://www.who.int/. https://www.who.int/(2020) Available at: https://www.who.int/

3. Pollan M, Perez-Gomez B, Pastor-Barriuso R, Oteo J, Hernán MA, Pérez-Olmeda M, Sanmartín JL, Fernández-García A, Cruz I, Larrea NF de, et al. A Population-Based Seroepidemiological Study of SARS-CoV-2 in Spain (ENE-COVID). Ssrn Electron J (2020) 22:535-544. doi:10.1016/s0140-6736(20)31483 
4. Gudbjartsson DF, Norddahl GL, Melsted P, Gunnarsdottir K, Holm H, Eythorsson E, Arnthorsson AO, Helgason D, Bjarnadottir K, Ingvarsson RF, et al. Humoral Immune Response to SARS-CoV-2 in Iceland. New Engl J Med (2020) 383:1724-1734. doi:10.1056/nejmoa2026116

5. Long Q-X, Tang X-J, Shi Q-L, Li Q, Deng H-J, Yuan J, Hu J-L, Xu W, Zhang Y, Lv F-J, et al. Clinical and immunological assessment of asymptomatic SARS-CoV-2 infections. Nat Med (2020) 26:1200-1204. doi:10.1038/s41591-020-0965-6

6. Iversen K, Bundgaard H, Hasselbalch RB, Kristensen JH, Nielsen PB, Pries-Heje M, Knudsen AD, Christensen CE, Fogh K, Norsk JB, et al. Risk of COVID-19 in health-care workers in Denmark: an observational cohort study. Lancet Infect Dis (2020) 20:1401-1408. doi:10.1016/s1473-3099(20)30589-2

7. Slot E, Hogema BM, Reusken CBEM, Reimerink JH, Molier M, Karregat JHM, IJlst J, Novotný VMJ, Lier RAW van, Zaaijer HL. Low SARS-CoV-2 seroprevalence in blood donors in the early COVID-19 epidemic in the Netherlands. Nat Commun (2020) 11:5744. doi:10.1038/s41467-020-19481-7

8. Tuells J, Egoavil CM, Pardo MAP, Montagud AC, Montagud E, Caballero P, Zapater P, Puig-Barberá J, Hurtado-Sanchez JA. Seroprevalence Study and Cross-Sectional Survey on COVID-19 for a Plan to Reopen the University of Alicante (Spain). Int J Environ Res Pu (2021) 18:1908. doi:10.3390/ijerph18041908

9. Araújo AA de S, Quintans-Júnior L, Schimieguel DM, Corrêa CB, Moura TR de, Cavalcante RCM, Grespan R, Cerqueira-Meneses D de V, Barreto-Alves JA, Martins-Filho PR. Seroprevalence of SARS-CoV-2 antibodies in low-income university students. Excli J (2021) 20:276-280. doi:10.17179/excli2021-3459

10. Tilley K, Ayvazyan V, Martinez L, Nanda N, Kawaguchi ES, O'Gorman M, Conti D, Gauderman WJ, Orman SV. A Cross-Sectional Study Examining the Seroprevalence of Severe Acute Respiratory Syndrome Coronavirus 2 Antibodies in a University Student Population. J Adolescent Health (2020) 67:763-768.

doi:10.1016/j.jadohealth.2020.09.001

11. Arnold CRK, Srinivasan S, Herzog CM, Gontu A, Bharti N, Small M, Rogers CJ, Schade MM, Kuchipudi SV, Kapur V, et al. SARS-CoV-2 Seroprevalence in a University Community: A Longitudinal Study of the Impact of Student Return to Campus on Infection Risk Among Community Members. Medrxiv Prepr Serv Heal Sci (2021) doi:10.1101/2021.02.17.21251942

12. Tsitsilonis OE, Paraskevis D, Lianidou E, Pierros V, Akalestos A, Kastritis E, Moutsatsou P, Scorilas A, Sphicopoulos T, Terpos E, et al. Seroprevalence of Antibodies against SARS-CoV-2 among the Personnel and Students of the National and Kapodistrian University of Athens, Greece: A Preliminary Report. Life (2020) 10:214. doi:10.3390/life10090214

13. Group. WB. The COVID-19 Crisis Reponse: Supporting Tertiary Education for Continuity, Adaptation, and Innovation., eds. W. B. Group. Washington, DC, USA, 2020 (n.d.).

14. Rostami A, Sepidarkish M, Leeflang M, Riahi SM, Shiadeh MN, Esfandyari S, Mokdad AH, Hotez PJ, Gasser RB. SARS-CoV-2 seroprevalence worldwide: a systematic review and meta-analysis. Clin Microbiol Infec (2020) 27:331-340. doi:10.1016/j.cmi.2020.10.020

15. Zhou Y, Chi J, Lv W, Wang Y. Obesity and diabetes as high-risk factors for severe coronavirus disease 2019 (Covid-19). Diabetes Metabolism Res Rev (2021) 37:e3377. doi:10.1002/dmrr.3377

16. Cornejo-Pareja IM, Gómez-Pérez AM, Fernández-García JC, Millan RBS, Luque AA, Hollanda A, Jiménez A, Jimenez-Murcia S, Munguia L, Ortega E, et al. Coronavirus disease 2019 (COVID-19) and obesity. Impact of 
obesity and its main comorbidities in the evolution of the disease. Eur Eat Disord Rev (2020) 28:799-815. doi:10.1002/erv.2770

17. Shastri MD, Shukla SD, Chong WC, Kc R, Dua K, Patel RP, Peterson GM, O'Toole RF. Smoking and COVID19: What we know so far. Resp Med (2020) 176:106237. doi:10.1016/j.rmed.2020.106237

18. Zhao J, Yang Y, Huang H, Li D, Gu D, Lu X, Zhang Z, Liu L, Liu T, Liu Y, et al. Relationship between the ABO Blood Group and the COVID-19 Susceptibility. (n.d.) doi:10.1101/2020.03.11.20031096

19. Lechien JR, Chiesa-Estomba CM, Place S, Laethem YV, Cabaraux P, Mat Q, Huet K, Plzak J, Horoi M, Hans S, et al. Clinical and epidemiological characteristics of 1420 European patients with mild-to-moderate coronavirus disease 2019. J Intern Med (2020) 288:335-344. doi:10.1111/joim.13089

20. Kontou PI, Braliou GG, Dimou NL, Nikolopoulos G, Bagos PG. Antibody Tests in Detecting SARS-CoV-2 Infection: A Meta-Analysis. Diagnostics (2020) 10:319. doi:10.3390/diagnostics10050319

21. Brauner JM, Mindermann S, Sharma M, Johnston D, Salvatier J, Gavenčiak T, Stephenson AB, Leech G, Altman G, Mikulik V, et al. Inferring the effectiveness of government interventions against COVID-19. Science (2021) 371:eabd9338. doi:10.1126/science.abd9338

22. Fisher KA, Tenforde MW, Feldstein LR, Lindsell CJ, Shapiro NI, Files DC, Gibbs KW, Erickson HL, Prekker ME, Steingrub JS, et al. Community and Close Contact Exposures Associated with COVID-19 Among Symptomatic Adults $\geq 18$ Years in 11 Outpatient Health Care Facilities — United States, July 2020. Morbidity Mortal Wkly Rep (2020) 69:1258-1264. doi:10.15585/mmwr.mm6936a5

23. Madewell ZJ, Yang Y, Longini IM, Halloran ME, Dean NE. Household Transmission of SARS-CoV-2. Jama Netw Open (2020) 3:e2031756. doi:10.1001/jamanetworkopen.2020.31756

24. Figueiredo-Campos P, Blankenhaus B, Mota C, Gomes A, Serrano M, Ariotti S, Costa C, Nunes-Cabaço H, Mendes AM, Gaspar P, et al. Seroprevalence of anti-SARS-CoV-2 antibodies in COVID-19 patients and healthy volunteers up to 6 months post disease onset. Eur J Immunol (2020) 50:2025-2040.

doi:10.1002/eji.202048970

25. Lijia S, Lihong S, Huabin W, Xiaoping X, Xiaodong L, Yixuan Z, Pin H, Yina X, Xiaoyun S, Junqi W. Serological chemiluminescence immunoassay for the diagnosis of SARS-CoV-2 infection. J Clin Lab Anal (2020) 34:e23466. doi:10.1002/jcla.23466

26. Hooper MW, Nápoles AM, Pérez-Stable EJ. COVID-19 and Racial/Ethnic Disparities. Jama (2020) 323:2466-2467. doi:10.1001/jama.2020.8598 


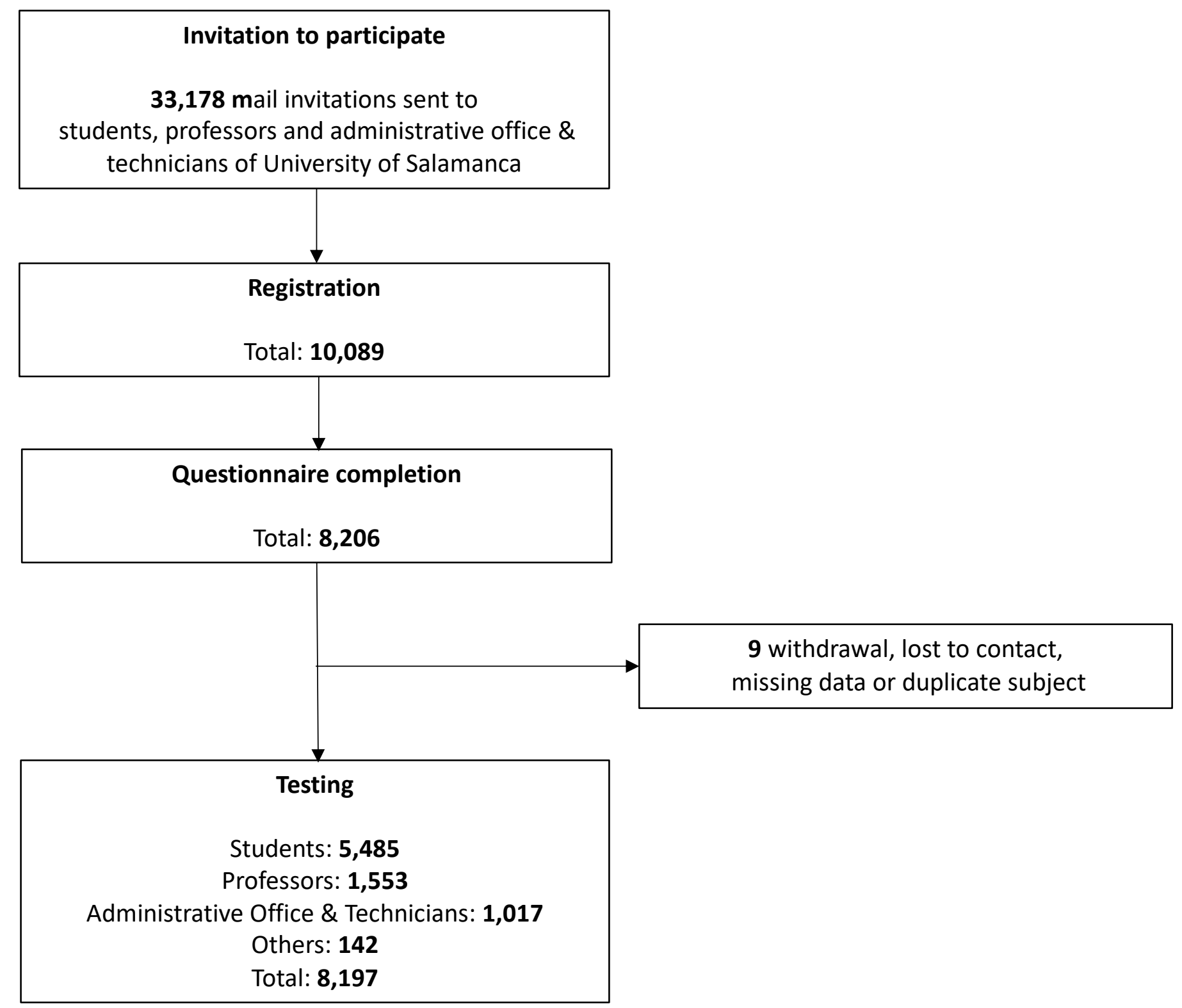

Figure 1. Participant flowchart through the recruitment process with eligibility screening, questionnaire completion and testing 

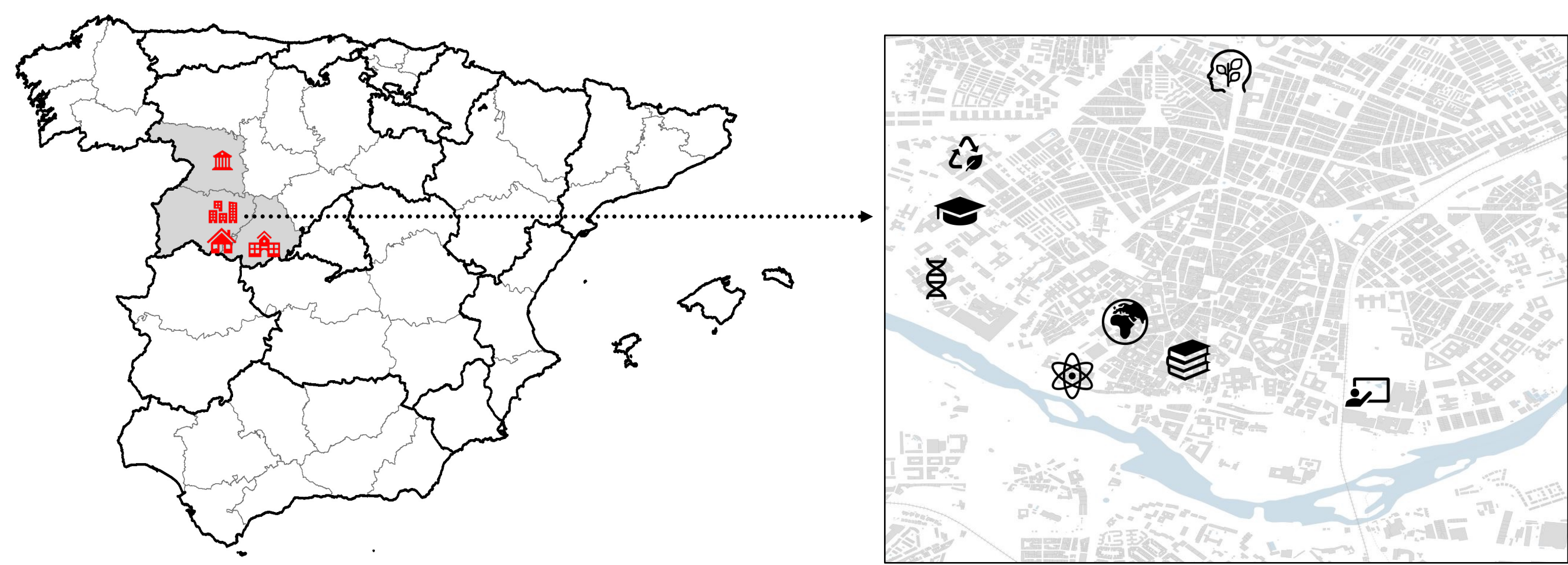

Education

2 Agriculture \&

E. Environment

Language

Geography 


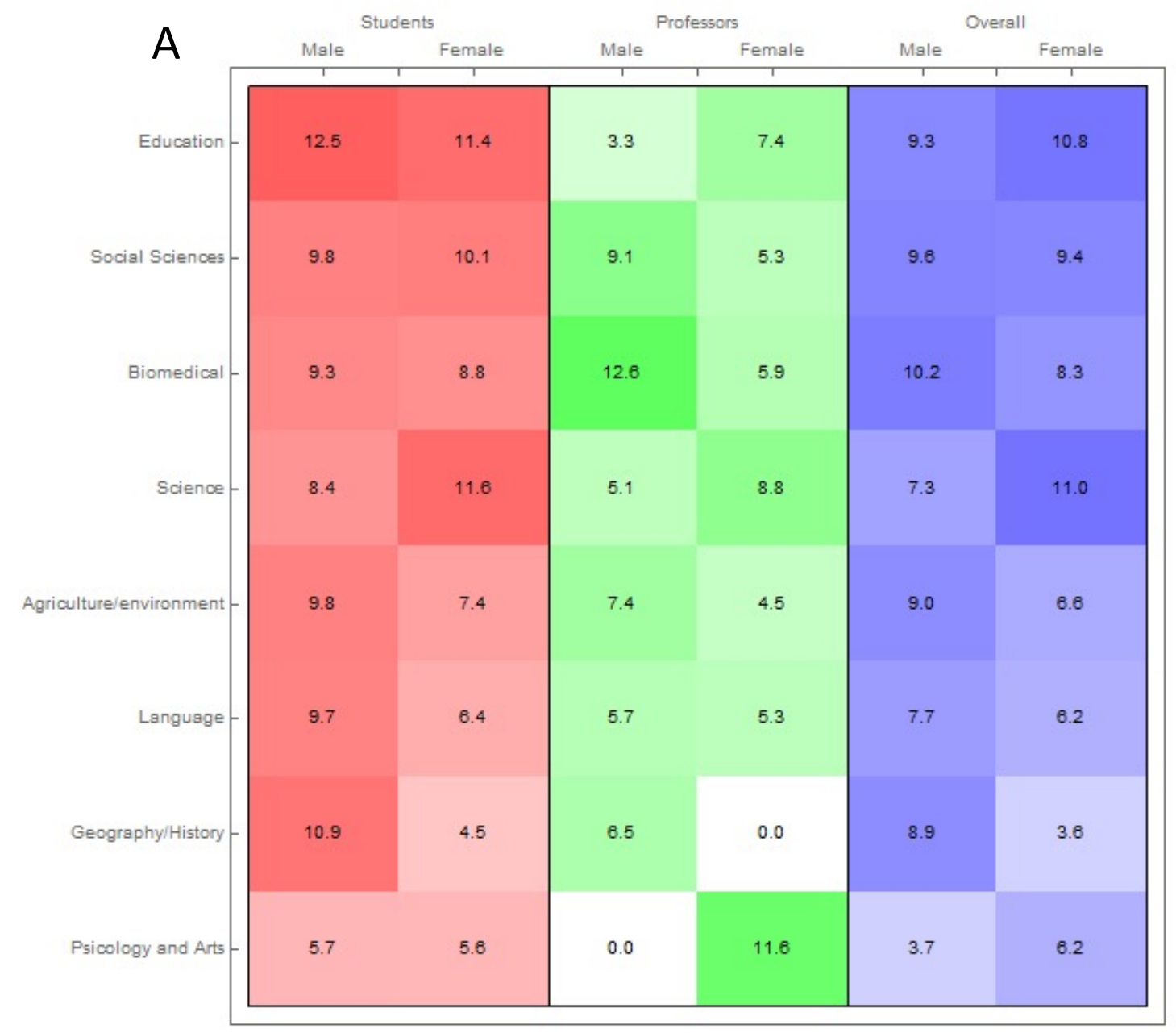

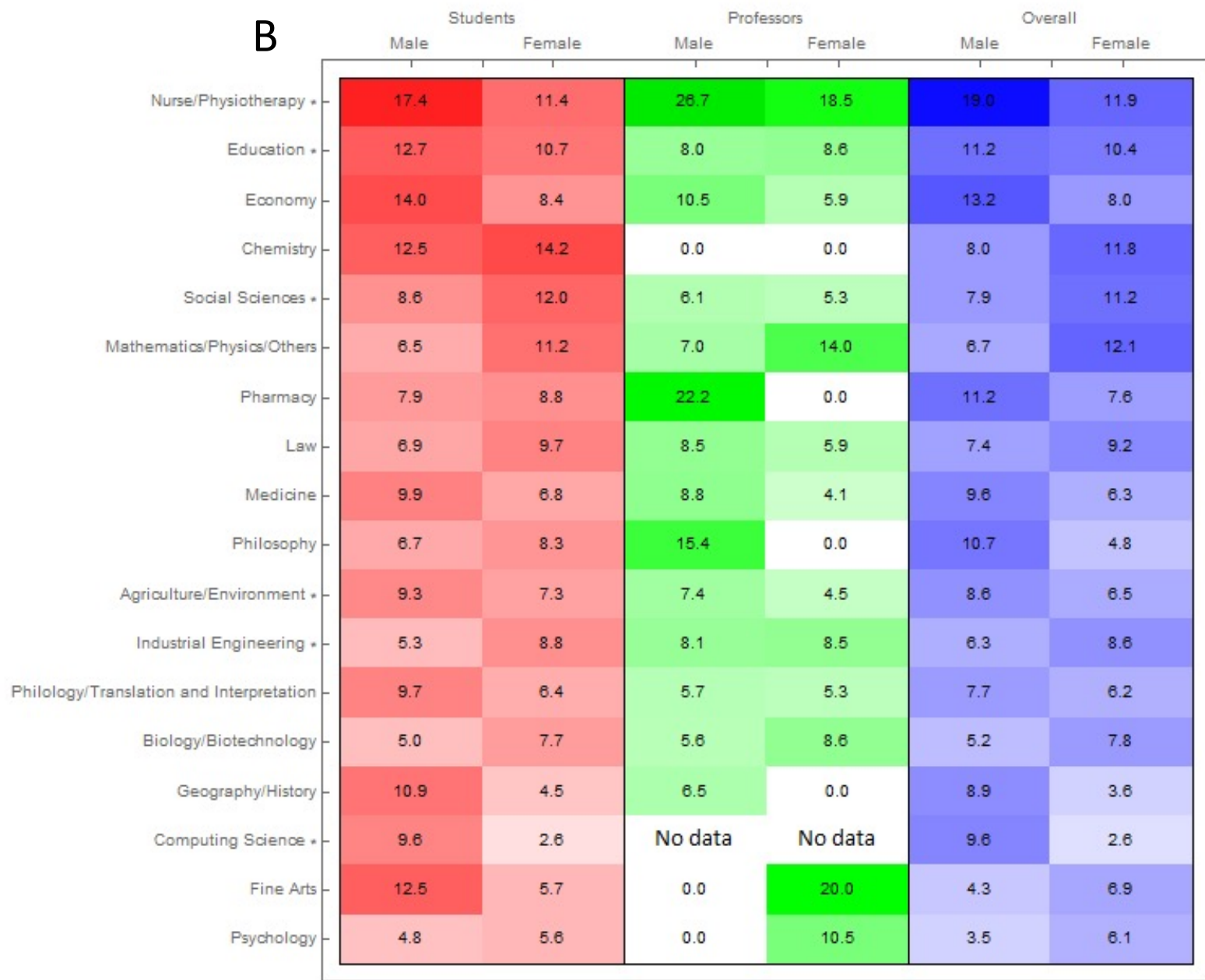

Figure 3. Seroprevalence in University of Salamanca Campus: A) Faculties in Salamanca city, B) Distribution according sex and position 

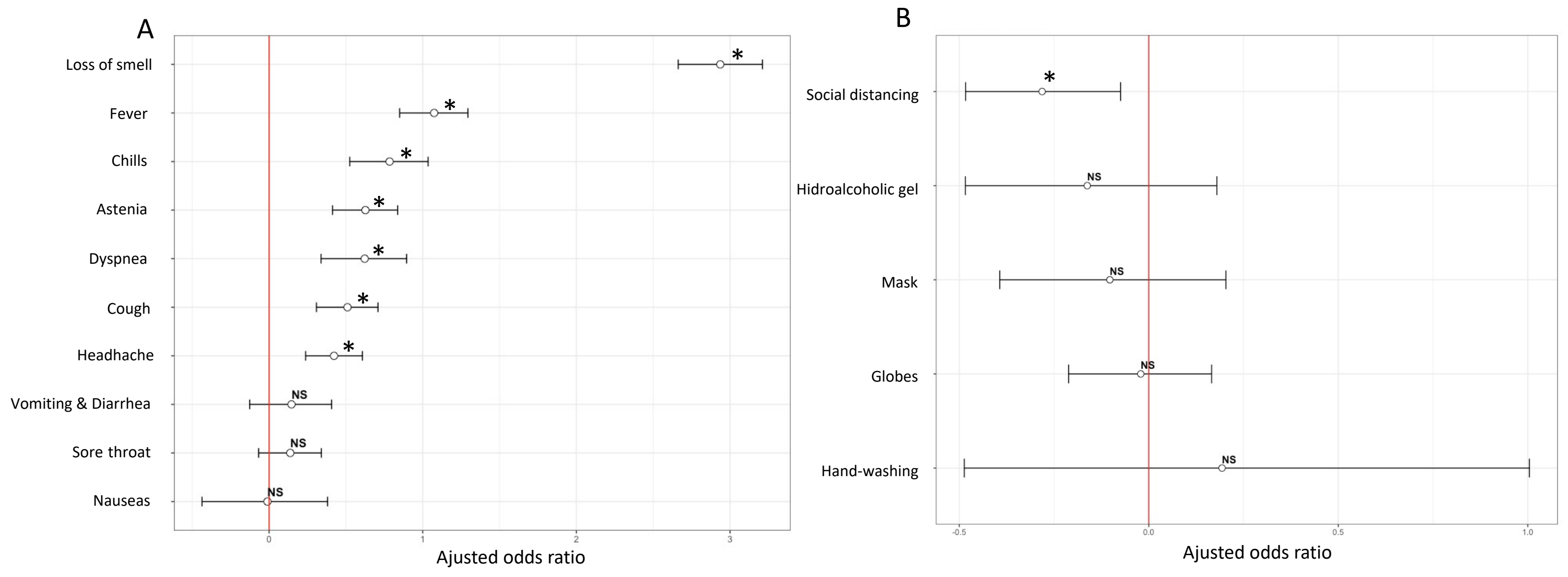

Figure 5. Adjusted odds-ratio and 95\% confidence intervals for community exposure associated with main symptoms (A) and hygiene measures (B) with COVID-19. ${ }^{*} p<0.05$. NS: Non significate 
Table 1. Main data according to the different demographic variables selected: age, sex, categories, location campus and faculty.

\begin{tabular}{|c|c|c|}
\hline \multicolumn{2}{|l|}{ Variables } & $N=8197(\%)$ \\
\hline \multicolumn{3}{|l|}{ Age } \\
\hline \multicolumn{2}{|c|}{ Mean $\pm \mathrm{SD}$; years } & $31.4 \pm 14.5$ \\
\hline \multirow{5}{*}{ Population } & $17-28$ & $5503(68.1 \%)$ \\
\hline & $29-39$ & $486(6.0 \%)$ \\
\hline & $40-49$ & $606(7.5 \%)$ \\
\hline & $50-59$ & 1039 (12.9\%) \\
\hline & $60-76$ & $441(5.5 \%)$ \\
\hline \multicolumn{3}{|l|}{ Sex } \\
\hline \multicolumn{2}{|l|}{ Male } & $2709(34.0 \%)$ \\
\hline \multicolumn{2}{|l|}{ Female } & $5248(66.0 \%)$ \\
\hline \multicolumn{3}{|l|}{ Position } \\
\hline \multirow{2}{*}{ Students } & Undergraduate & $5093(62.1 \%)$ \\
\hline & Postgraduate (Master \& PhD) & $392(4.8 \%)$ \\
\hline \multicolumn{2}{|l|}{ Professors } & $1553(18.9 \%)$ \\
\hline \multicolumn{2}{|c|}{ Technicians \& Administrative Officers } & $1017(12.4 \%)$ \\
\hline \multicolumn{2}{|l|}{ Others } & $142(1.7 \%)$ \\
\hline \multicolumn{3}{|c|}{ Salamanca University Campus Map } \\
\hline \multicolumn{2}{|l|}{ Salamanca } & $7390(90.2 \%)$ \\
\hline \multicolumn{2}{|l|}{ Zamora } & $355(4.3 \%)$ \\
\hline \multicolumn{2}{|l|}{ Avila } & $334(4.1 \%)$ \\
\hline \multicolumn{2}{|l|}{ Bejar } & $118(1.4 \%)$ \\
\hline \multicolumn{3}{|c|}{ Salamanca University Campus } \\
\hline \multicolumn{2}{|c|}{ Agriculture \& Environment } & $160(2.2 \%)$ \\
\hline \multicolumn{2}{|l|}{ Biomedical } & $1791(24.2 \%)$ \\
\hline \multicolumn{2}{|l|}{ Education } & $456(6.2 \%)$ \\
\hline \multicolumn{2}{|c|}{ Geography \& History } & $215(2.9 \%)$ \\
\hline \multicolumn{2}{|l|}{ Language } & $601(8.1 \%)$ \\
\hline \multicolumn{2}{|c|}{ Psychology and Arts } & $580(7.8 \%)$ \\
\hline \multicolumn{2}{|l|}{ Science } & $687(9.3 \%)$ \\
\hline \multicolumn{2}{|c|}{ Social Sciences } & 1408 (19.1\%) \\
\hline \multicolumn{2}{|l|}{ Others } & $1492(20.2 \%)$ \\
\hline
\end{tabular}


Table 3. Seroprevalence relationship with dwelling and exposure

\begin{tabular}{|c|c|c|c|c|}
\hline \multicolumn{2}{|c|}{ Dwelling \& exposure } & \multirow[t]{2}{*}{$N=7034(\%)$} & \multicolumn{2}{|c|}{ Seropositivity } \\
\hline & & & $N(\%)$ & $p$-value \\
\hline \multirow{3}{*}{ Residence } & Professors & $1549(22.0 \%)$ & $114(7.4 \%)$ & \multirow[t]{3}{*}{0.133} \\
\hline & Student private house & $5039(71.6 \%)$ & 449 (8.9\%) & \\
\hline & Student colleges & 446 (6.3\%) & $42(9.4 \%)$ & \\
\hline \multirow[t]{2}{*}{ Life with animals } & Yes & $1867(22.8 \%)$ & $138(7.4 \%)$ & \multirow[t]{2}{*}{0.127} \\
\hline & No & $6330(77.2 \%)$ & $538(8.5 \%)$ & \\
\hline \multirow[t]{3}{*}{ Exposure } & Household & $637(8.0 \%)$ & $189(29.7 \%)$ & \multirow[t]{3}{*}{0.000} \\
\hline & No household & 7049 (88.2\%) & 436 (6.2\%) & \\
\hline & Not know & $302(3.8 \%)$ & $31(10.3 \%)$ & \\
\hline \multirow[t]{2}{*}{ Household Exposure } & Colleges & $38(6.0 \%)$ & $13(34.2 \%)$ & \multirow[t]{2}{*}{0.583} \\
\hline & Private house & 599 (94.0\%) & $176(29.4 \%)$ & \\
\hline
\end{tabular}




\section{Supplementary Figure 1}

QUESTIONNAIRE

\section{Welcome to the DIANCUSAL clinical-epidemiological questionnaire}

\section{Weight and height data}

Height (in cm.) *

Weight (in kg.)*

\section{Information about your home during the $20 / 21$ academic year}

Type of residence* Apartment / University Residence

If you live in an apartment, square meters of your home

If you live in a residence, Name of the university residence

Place of your habitual residence*

Place of confinement*

Number of habitual partners*

Number of partners during confinement $*$

Pets

YES / NO
Postal Code

Cod. Confinement postcard
Number

Species

\section{Clinical data}

Toxic Habits

No / Smoker / Alcohol / Other drugs

Medical antecedents

Blood group

Diseases

Number of chronic medications
$\mathrm{A} / \mathrm{B} / \mathrm{AB} / \mathrm{O} /$ No I know

[write another disease] / Arterial Hypertension (HBP) / Diabetes Mellitus (DM) / Cardiovascular Risk Asthma / Chronic Obstructive Pulmonary Disease / Immunosuppression /

Cardiovascular Pathology / Chronic kidney failure

Types of medications 


\section{COVID Diagnosis Have \\ you been diagnosed with COVID?}

If the previous answer is affirmative, have

you required hospitalization?

Date of admission

Place of hospitalization

Date of discharge

Briefly explain the reasons for admission

\section{YES / NO}

YES / NO

\section{Clinical Evolution}

4. If you have not been diagnosed with COVID, have you had any of these symptoms?

Do you think you may have had COVID?

Fever

Cough

Sore throatSevere

Chills

Tiredness

Feeling short of breath

Headache

Nausea

Vomiting and / or diarrhea

Sudden loss of sense of smell or taste

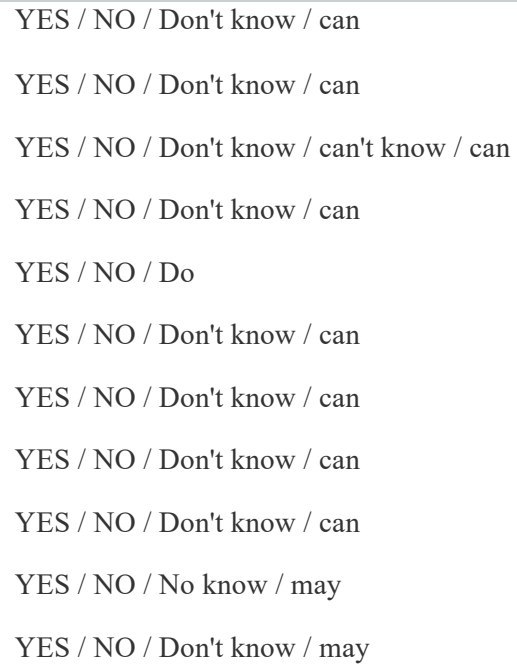

\section{COVID-19 diagnosis of a COVID-19:any}

Hascohabitant been diagnosed with COVID?

YES / NO / Don't know / can

how many?

Age / Ages

Degree of familiarity

Have they required hospitalization?

6. Even though no COVID-19 has been diagnosed with COVID, do you know if they have had any of these symptoms? 
Do you think that a partner may have had COVID even though it has not been confirmed?

Fever

Cough

Sore throatSevere

Chills

Tiredness

Feeling short of breath

Headache

Nausea

Vomiting and / or diarrhea

sudden loss of sense of taste or smell
YES / NO / Don't know / can

YES / NO / Don't know / can

YES / NO / Don't know / cann't know / can

YES / NO / Don't know / can

YES / NO / Do

YES / NO / Don't know / can

YES / NO / Don't know / can

YES / NO / Don't know / can

YES / NO / Don't know / can

YES / NO / No know / can

YES / NO / Do not know / can 


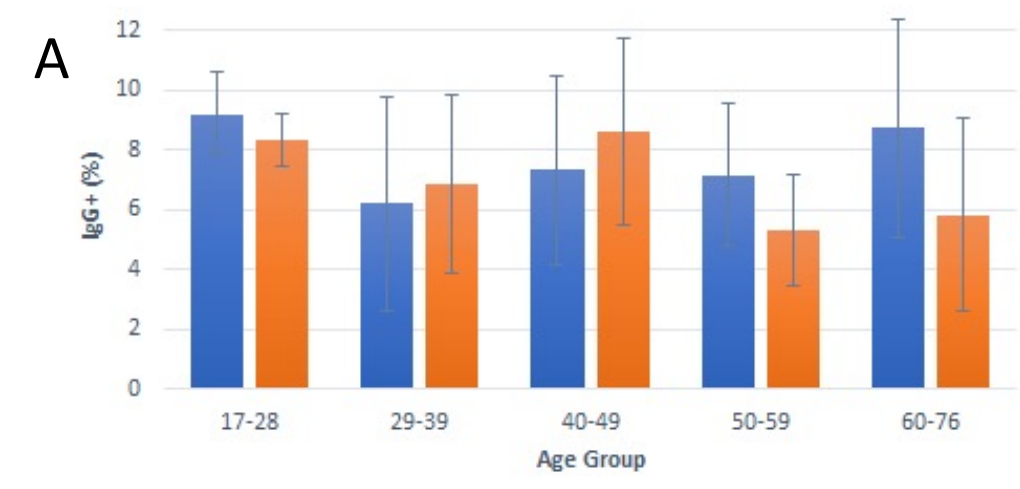

$$
\text { B }
$$
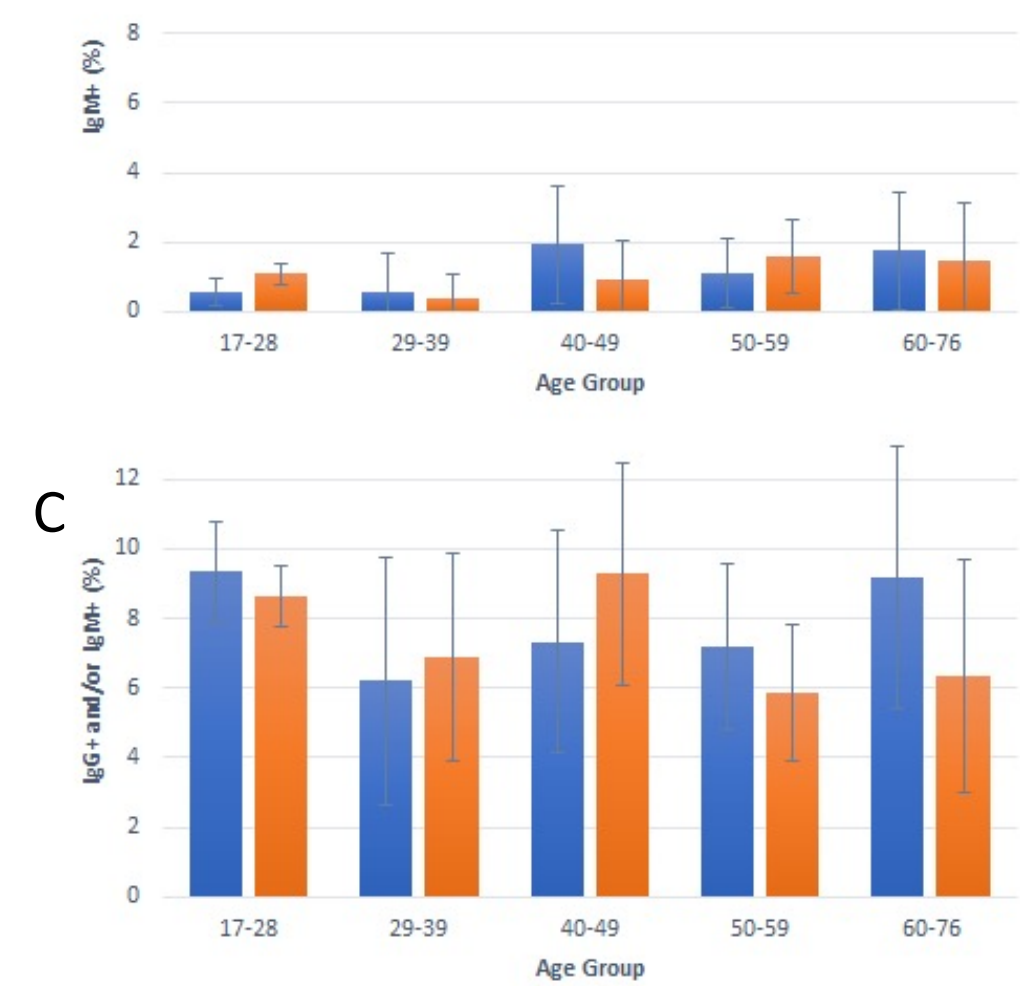

Supplementary figure 2 . Seroprevalence by sex and age group: A) IgG antibodies, B) IgM antibodies and C) IgG and/or IgM antibodies 


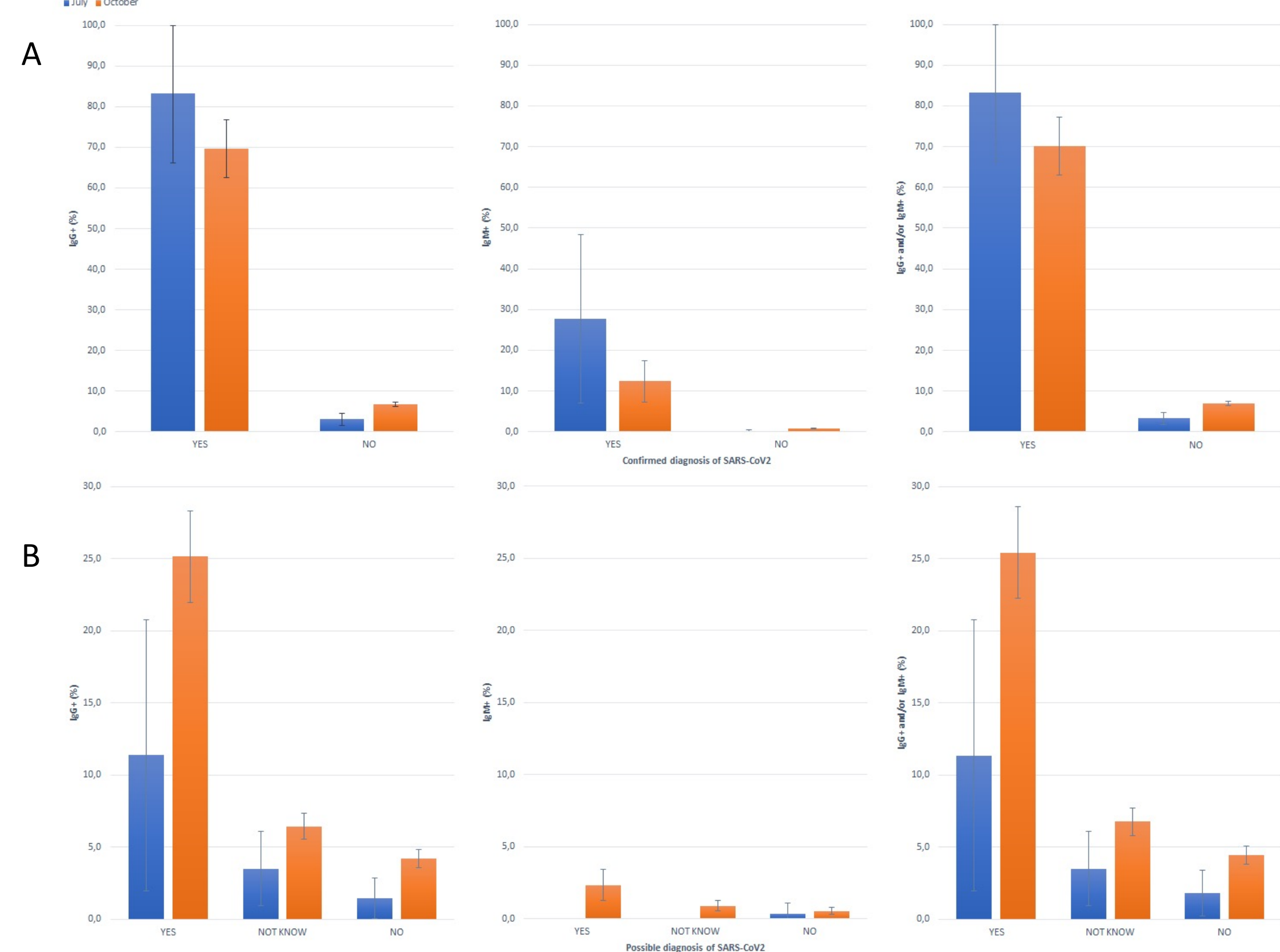

Supplementary figure 3. Seroprevalence according to the time of the serology A) Confirmed diagnosis of SARS-CoV2, B) Possible diagnosis of SARS-CoV2 
Supplementary table 1. Seroprevalence of IgG \& IgM antibodies according to blood types and Body Mass Index (BMI)

\begin{tabular}{|c|c|c|c|c|c|c|c|c|c|c|}
\hline Blood type \& & $N=8197(\%)$ & \multicolumn{3}{|c|}{$\lg G+$} & \multicolumn{3}{|c|}{$\lg M+$} & \multicolumn{3}{|c|}{ IgG+ and/or lgM+ } \\
\hline Body mass index & & $\mathrm{N}=\mathrm{n}(\%)$ & \multicolumn{2}{|c|}{$p$-value } & $\mathrm{N}=\mathrm{n}(\%)$ & \multicolumn{2}{|l|}{ p-value } & $\mathrm{N}=\mathrm{n}(\%)$ & \multicolumn{2}{|l|}{$p$-value } \\
\hline Blood type & $\mathrm{N}=5210(\%)$ & & & & & & & & & \\
\hline 0 & $2102(40.3 \%)$ & $159(7.6 \%)$ & \multirow{4}{*}{\multicolumn{2}{|c|}{0.147}} & $23(1.1 \%)$ & \multirow{4}{*}{\multicolumn{2}{|c|}{0.752}} & $167(7.9 \%)$ & \multirow{4}{*}{\multicolumn{2}{|c|}{0.110}} \\
\hline A & $2463(47.3 \%)$ & $221(9.0 \%)$ & & & $33(1.3 \%)$ & & & $227(9.2 \%)$ & & \\
\hline B & $454(8.7 \%)$ & $30(6.6 \%)$ & & & $4(0.9 \%)$ & & & $30(6.6 \%)$ & & \\
\hline$A B$ & $191(3.7 \%)$ & 19 (9.9\%) & & & $3(1.6 \%)$ & & & $21(11.0 \%)$ & & \\
\hline Body Mass Index (BMI) & $\mathrm{N}=8183(\%)$ & $\mathrm{N}=\mathrm{n}(\%)$ & OR $95 \% \mathrm{Cl}$ & $p$-value & $\mathrm{N}=\mathrm{n}(\%)$ & OR $95 \% \mathrm{Cl}$ & $p$-value & $\mathrm{N}=\mathrm{n}(\%)$ & OR $95 \% \mathrm{Cl}$ & p-value \\
\hline$<18.5$ & $560(6.8 \%)$ & $41(7.3 \%)$ & \multirow{5}{*}{$\begin{array}{c}1.009 \\
{[0.988,1.029]}\end{array}$} & \multirow[t]{5}{*}{0.415} & $4(0.7 \%)$ & \multirow[t]{5}{*}{$1.013[0.960,1.069]$} & \multirow[t]{5}{*}{0.637} & $43(7.7 \%)$ & \multirow[t]{5}{*}{$1.006[0.986,1.027]$} & \multirow[t]{5}{*}{0.541} \\
\hline $18.5-24.9$ & $5486(67.0 \%)$ & $443(8.1 \%)$ & & & $54(1.0 \%)$ & & & $459(8.4 \%)$ & & \\
\hline $25-29.9$ & 1665 (20.3\%) & $133(8.0 \%)$ & & & $25(1.5 \%)$ & & & $137(8.2 \%)$ & & \\
\hline $30-34.9$ & $385(4.7 \%)$ & $31(8.1 \%)$ & & & $2(0.5 \%)$ & & & $31(8.1 \%)$ & & \\
\hline$>35$ & $87(1.1 \%)$ & $6(6.9 \%)$ & & & $0(0.0 \%)$ & & & $6(6.9 \%)$ & & \\
\hline
\end{tabular}


Figures

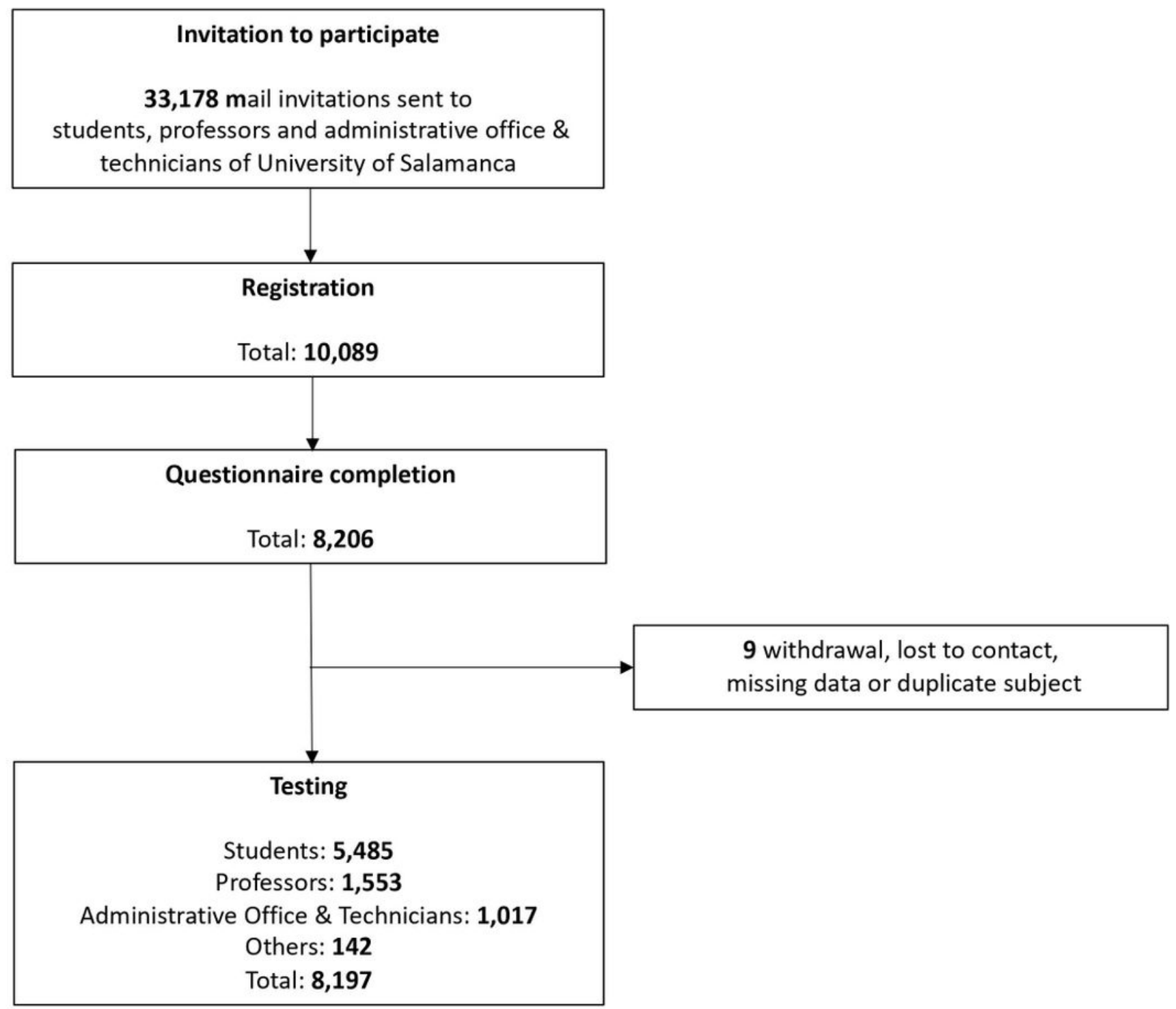

\section{Figure 1}

Participant flowchart through the recruitment process with eligibility screening, questionnaire completion and testing 



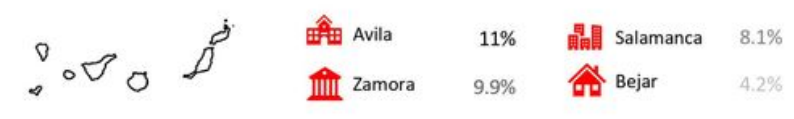

Figure 2

Seroprevalence of University of Salamanca: A) main towns and B) Salamanca city campus Note: The designations employed and the presentation of the material on this map do not imply the expression of any opinion whatsoever on the part of Research Square concerning the legal status of any country, territory, city or area or of its authorities, or concerning the delimitation of its frontiers or boundaries. This map has been provided by the authors.


\section{Figure 3}


Seroprevalence in University of Salamanca Campus: A) Faculties in Salamanca city, B) Distribution according sex and position
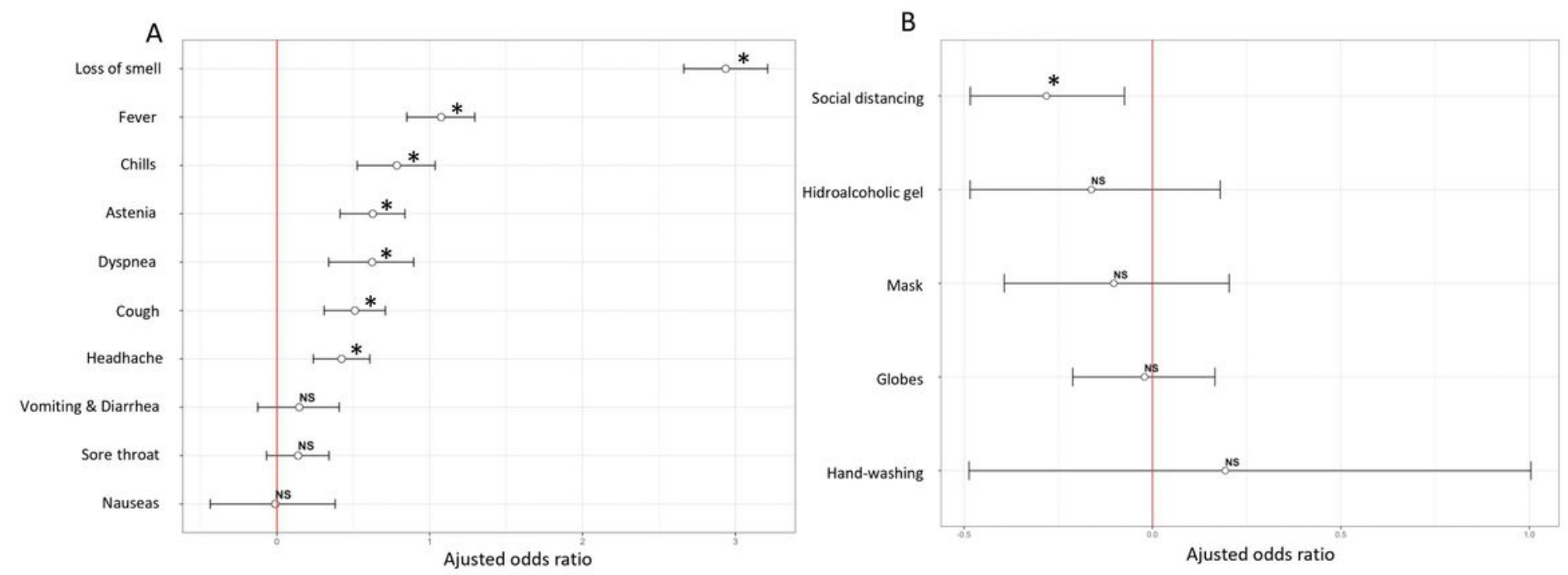

\section{Figure 4}

Adjusted odds-ratio and $95 \%$ confidence intervals for community exposure associated with main symptoms (A) and hygiene measures (B) with COVID-19. ${ }^{*}<<0.05$. NS: Non significate 